\title{
Die Heimat des Staunens
}

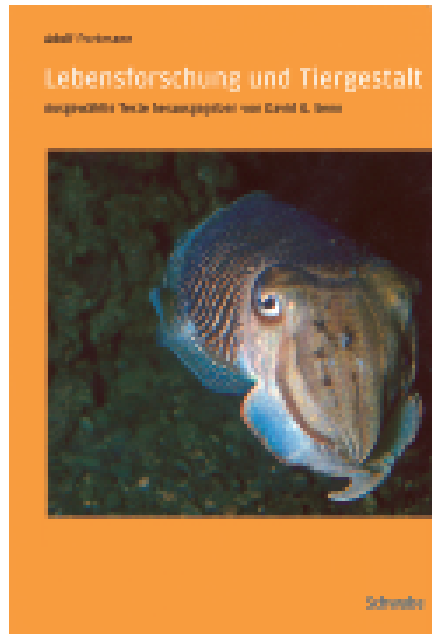

* A. Portmann

Lebensforschung und Tiergestalt. Ausgewählte Texte, herausgegeben von David G. Senn.

Basel: Schwabe; 2006. $231 \mathrm{~S}$

ISBN 3-7965-2172-X.
Auf einer gigantischen Mittelmeerfähre, 20 Meter über der Wasseroberfläche an der Reling stürmischen Windböen ausgesetzt, kann es einem passieren, dass man unversehens zu einem Erlebnis intensiven Staunens kommt. Und das geht so: Man klemmt ein Stück Brot von der Grösse eines Würfelzuckers zwischen Daumen und Zeigefinger zum Beispiel der rechten Hand je nachdem, ob man sich steuerbord oder backbord positioniert hat -, hält den gestreckten Arm ruhig in einer Abduktionsstellung von 90 (es darf auch ein bisschen mehr sein) über das Geländer hinaus und wartet.

Alsbald taucht sie auf: Ein grosse Möwe gleitet luvseitig in leichter Schräglage heran und geht rund fünf Meter hinter der dargebotenen Hand in Position.

Nein, mein Freund, das schaffst Du nie im Leben, denkt man sich angesichts der mit perfider Unregelmässigkeit zuschlagenden Windstösse, die den eleganten Segler wie gut getimte Schläge eines Boxers ins Trudeln bringen und eher zehn als fünf Meter weit abdriften lassen. Damit die Sache nicht zu einfach wird, tut sich zur Abwechslung auch mal ein Luftloch auf, oder der Vogel wird aus unheiterem Himmel in die Höhe katapultiert. Der neugewonnene Freund bleibt gelassen, tastet sich Anlauf um Anlauf näher an den Bissen ran. Noch 1 Meter - eine Böe wirft ihn seitlich aus der Bahn. Noch $50 \mathrm{~cm}$ - die Luftschicht unter ihm scheint wegzubrechen, und er findet sich zwei Etagen tiefer wieder. Doch dann - Sie haben es bereits geahnt - ist er da, der Moment, in dem alles stimmt: Wie ein Surfer auf der Welle gleitet die Möwe schräg nach unten, balanciert kleinere Turbulenzen spielerisch aus, leitet kurz vor dem Ziel eine elegante Auswärtsdrehung ein und schnappt sich en passant den Lohn ihrer meisterlichen Kür.

Ein Erlebnis, das längst in den Tiefschlaf versunkene Erinnerungen weckt. Etwa an einen Ordinarius für Neuroinformatik, der im Gespräch einmal trocken - und eher überraschend - bemerkte, im Vergleich mit der Leistung einer Biene, die «ihre» Blüte ansteure und sich daran gütlich tue, sei ein moderner Supercomputer geradezu unglaublich dumm.

In noch stärkerem Masse lässt die Kunst der Möwe indes Sätze aus dem bemerkenswerten Buch «Lebensforschung und Tiergestalt» lebendig werden, das ausgewählte Texte des grossen Basler Biologen Adolf Portmann (1897-1982) enthält*. Sätze wie diesen: «Wer sich Jahrzehnte hindurch bemüht hat, unsere Einsicht in die Beziehungen zwischen Form und Funktion am Beispiel der Vogelfeder zu vertiefen, wie wir dies in meinem Laboratorium getan haben, der darf auch immer wieder auf Gestaltungen hinweisen, die sich einer solchen Deutung entziehen.» Oder: «Das Ahnen der unergründlichen Weite der Wirklichkeit, die uns als gewaltige Einheit umschliesst, die unser ganzes Wesen mit enthält dieses Ahnen verlangt, dass unser vom Verstand geordnetes Weltbild als unvollendet erfasst und durch die Imagination verborgener Zusammenhänge in immer erneuten Versuchen ergänzt wird».

Portmann war kein unwissenschaftlicher Schwärmer, im Gegenteil, er erwarb sich internationale Anerkennung durch exakte biometrische Arbeiten zu Entwicklung und Wachstum bei höheren Wirbeltieren, wobei er der Hirnentwicklung besondere Aufmerksamkeit schenkte. Aber er blieb nicht bei denjenigen Erscheinungsformen des Lebendigen stehen, die sich nahtlos und widerspruchsfrei ins Gefüge etablierter Modellstrukturen einfügen. Sein Geist wurde durch Phänomene herausgefordert, die sich gängigen biologisch-funktionalen Deutungen entziehen. Eine Eigenschaft, die er mit vielen Grossen der Wissenschaftsgeschichte teilt. Erst kürzlich führte der Zoologe Günter Tembrock, auch er eine Koryphäe, in einem WeltwocheInterview als evolutionstheoretische «Knacknuss» das Beispiel einer in Erdhöhlen lebenden Eulenart an, die potentielle Angreifer durch Imitation der Rasselgeräusche von Klapperschlangen abschreckt: «Ein spannendes und für die Evolutionsbiologie sehr schwieriges Thema. Es ist unglaublich schwer vorstellbar, wie durch einfache Selektion aus einem Eulenschrei ein Schlangenklappern wurde.»

Nur indem man solchen Fragestellungen nicht ausweicht, kommt letztlich wissenschaftlicher Fortschritt zustande. In den Grenzbereichen, wo das Staunen beheimatet ist, weil die Theorie die wahrnehmbare Wirklichkeit nicht mehr befriedigend erklärt, finden sich die wissenschaftlichen Herausforderungen. Ob sie sich denn immer mit dem Instrumentarium der Wissenschaft erklären lassen, muss eine offene Frage bleiben, solange es solche «Geheimnisse» gibt.

Bruno Kesseli 